\title{
ESTE "NEGÓCIO" É POLISSEMIA OU HOMONÍMIA?
}

\section{IS THIS “NEGÓCIO” POLYSEMY OR HOMONYMY?}

Letícia Lemos Gritti

Universidade Tecnológica Federal do Paraná, Pato Branco, Paraná, Brasil

Sandra Mara Fernandes dos Santos

Universidade Tecnológica Federal do Paraná, Pato Branco, Paraná, Brasil

Lovania Roehrig Teixeira

Universidade Tecnológica Federal do Paraná, Pato Branco, Paraná, Brasil

Robson Deon

Universidade Federal do Mato Grosso do Sul, Aquidauana, Mato Grosso do Sul, Brasil

\begin{abstract}
Resumo: Este artigo, a partir de um ponto de vista semântico, analisa o item lexical "negócio" usado em diferentes contextos no Português Brasileiro, desde os mais formais até os mais informais. Analisam-se as características do item, utilizando o conceito de ambiguidade. Tal fenômeno diz respeito à capacidade múltipla de significado que uma mesma palavra pode ter em determinados contextos. Mais especificamente, o estudo procura esclarecer se a ambiguidade lexical da palavra "negócio" é gerada por polissemia e/ou homonímia, dois tipos particulares de ambiguidade. As principais concepções teóricas são de Ilari e Geraldi (1987), Ilari (2002), Cambrussi e Poll (2015), Ferraz (2014), Pustejovsky, (1995) e Lyons (1977). Após análises, verificou-se que a palavra "negócio" pode tanto apresentar usos em que apresenta ambiguidade por polissemia quanto ambiguidade por homonímia. Até onde se pode verificar, esse tipo de análise de "negócio" é inédito na literatura linguística.
\end{abstract}

Palavras-chave: Polissemia; Homonímia; Semântica; Ambiguidade; Negócio

Abstract: This article analyzes the item "negócio" from a semantic point of view. This expression is used in different contexts - formal and informal ones - in Brazilian Portuguese. "negócio" is discussed using the concept of ambiguity, which is the multiple capacity of signification of a word in certain contexts. More specifically, this study investigates if the lexical ambiguity of "negócio" is generated by Polysemy or/and by Homonymy, two different types of ambiguities. The main concepts came from the following works: Ilari and Geraldi (1987), Ilari (2002), Cambrussi and Poll (2015), Ferraz (2014), Pustejovsky, (1995) and Lyons (1977). We conclude that "negócio" is able to establish a semantic relation of ambiguity either by polysemy or by homonymy, depending on the linguistic context.

Keywords: Polysemy; Homonymy; Semantics; Ambiguity; Negócio 


\section{INTRODUÇÃO}

Um dos tópicos que mais intriga os linguistas, sobretudo os semanticistas, é o fato de muitas das palavras das línguas naturais possuírem mais de um significado e, ainda assim, os falantes nativos saberem utilizar tais itens nos contextos adequados. Uma das provas de que as palavras possuem, em sua maioria, mais de um significado são os verbetes dos dicionários. Após uma consulta a qualquer dicionário, verificamos que não é possível encontrar uma palavra que tenha apenas um significado listado. Isso gera dificuldades tanto para falantes nativos de uma língua, quanto para os aprendizes de uma segunda língua.

$\mathrm{Na}$ maioria dos casos, a escolha por um ou por outro significado só é resolvida quando consideramos o contexto linguístico ou extralinguístico (lugar, tempo, interlocutores) do proferimento. Por exemplo, a palavra "canto" na seguinte sentença:

\section{(1) Ninguém valoriza o meu canto.}

pode se referir ao ato de cantar, se o interlocutor é o Lulu Santos (um cantor). Ou também, pode-se referir à moradia (metaforicamente), se o interlocutor estiver reclamando da sujeira que os amigos deixaram no seu apartamento; ou ainda, pode dizer respeito ao lugar onde se encontram duas paredes, quando o interlocutor é um pedreiro que está numa disputa (com outros pedreiros) em que vence quem demonstrar a capacidade de construir um canto com um ângulo perfeito. No caso de (1), temos um contexto extralinguístico que ajuda na resolução da ambiguidade. desfeita:

No exemplo (2), o contexto linguístico colabora para que a ambiguidade seja

(2) a. Estou fazendo aula com uma soprano e tocando toda noite em barzinhos, ainda assim, ninguém valoriza o meu canto.

b. Você mora numa enorme casa com piscina, por isso ninguém (da família) valoriza o meu canto.

c. Coloca a luminária mais para a direita, talvez isso valorize aquele canto.

A esse fenômeno da multiplicidade de sentidos de expressões linguísticas, chamamos de ambiguidade. Conforme Ilari e Geraldi (1987), a ambiguidade ocorre nos mais diversos níveis linguísticos, o lexical, o estrutural ou sintático, ou ainda aquela relacionada ao escopo, a depender da forma linguística utilizada.

Neste trabalho, vamos nos deter à ambiguidade lexical, que trata da multiplicidade de sentidos que um item lexical pode apresentar, uma vez que o nosso objeto de estudos é o termo "negócio" e os seus vários significados. A ambiguidade lexical subdivide-se em algumas classes, a citar a homonímia e a polissemia. Neste artigo, vamos investigar em qual das duas classes o item lexical "negócio" se encaixa. Para fazer isso, primeiro apresentamos as concepções de ambiguidade por polissemia e por homonímia. Na seção seguinte, fazemos uma breve discussão sobre o método e o corpus de pesquisa. Na seção subsequente, discutimos os dados e os achados dentro do viés semântico. E, finalmente, apresentamos as considerações finais.

\section{ALGUMAS PALAVRAS SOBRE AMBIGUIDADE}

Um dos primeiros a falar sobre ambiguidade foi Aristóteles (1996) ao dizer que há um número finito de nomes e um número infinito de coisas, definições, etc., o que, resulta, segundo ele, em ambiguidades. No que diz respeito à ambiguidade lexical, o filósofo a caracteriza como ambiguidade de duplo sentido do termo em si, o hábito de acessar um único 
nome com diversos significados.

Lyons (1987) pauta sua definição de ambiguidade no sentido negativo desse fenômeno. Para o linguista, a ambiguidade consiste em uma forma linguística que codifica mais de uma mensagem e ela pode vir de uma imperfeição do falante ou deficiência do código da língua. Depois dessa concepção surgiram outras e inúmeros tipos de ambiguidade foram sendo apontadas pela literatura. lexical:

Considere a palavra "banco" na sentença abaixo que exemplifica a ambiguidade

(3) Eu estou no "banco".

Vemos que (i) o elemento que gera ambiguidade é o item "banco"; (ii) há, no mínimo dois significados para a palavra e, por isso, duas leituras para a sentença em (3) ${ }^{1}$, as quais podem ser parafraseadas como (4) e (5):

(4) O falante está na instituição financeira.

(5) O falante está no assento descansando.

Sendo assim, em (3) temos um exemplo de ambiguidade lexical em que um único item lexical é responsável pela multiplicidade de leituras da sentença. Note que em (3), é o contexto extralinguístico que resolve a ambiguidade. Para que o contexto linguístico deixasse clara a leitura, para cada um dos casos, teríamos que ter algo como as seguintes sentenças.

(6) Eu estou no "banco", vim trocar um cheque que tinha sido preenchido errado.

(7) Eu estou no "banco", corri demais e resolvi descansar um pouco.

Tendo em vista que (i) estamos interessados na multiplicidade semântica do item lexical "“"negócio"” que tem uso bastante produtivo no Português Brasileiro (PB) e (ii) acreditamos que a ambiguidade gerada nas sentenças em que o "negócio" ocorre decorre exclusivamente da semântica do item lexical, discutimos se o tipo de ambiguidade envolvido é homonímia e/ou polissemia. Weinreich (1964) caracteriza a homonímia como um tipo de ambiguidade contrastiva, em que há dois ou mais sentidos distintos que não apresentam relação de significado entre si; a polissemia, por sua vez, é um tipo de ambiguidade complementar, i.e., um item lexical apresenta sentidos relacionados entre si. Todos esses aspectos serão mais bem tratados nas seções seguintes.

\subsection{AMBIGUIDADE POR POLISSEMIA}

Quando os diferentes sentidos de um item lexical ambíguo se relacionam semanticamente entre si de alguma forma, e de maneira mais ou menos aproximada, estamos diante da ambiguidade por polissemia.

Assim, como afirmam Cambrussi e Poll (2015, p. 126), com base em Lyons (1977), Pustejovsky (1995) e Ferraz (2014), "palavras polissêmicas não são uma coincidência de formas", como as palavras homonímicas, "mas casos em que diferentes significados podem ser atribuídos a um mesmo item lexical e esses significados estão relacionados por acepções básicas" (CAMBRUSSI;POLL, 2015, p. 126).

Assim, além da coincidência da forma fônica, gráfica e sintática das palavras, seus possíveis e múltiplos significados semânticos se relacionam em alguma medida. Ou seja, apesar dos diferentes significados, há certos traços que as interligam. A multiplicidade, de

\footnotetext{
${ }^{1}$ Não trataremos do dêitico 'eu', pois esse tópico foge ao escopo do presente artigo.
} 
certa forma, encontra um ponto de convergência e/ou unidade.

Para exemplificar esse tipo de ambiguidade, Ferraz (2014) aponta a palavra "igreja". Esse termo pode ter basicamente três sentidos diferentes: (i) espaço físico; (ii) instituição religiosa; (iii) um grupo de pessoas que frequenta determinada instituição religiosa:

(8) João mora perto da "igreja".

(9) João se converteu na "igreja" Católica.

(10) Nós somos "igreja", por isso, conte conosco.

É importante frisar que é por meio do contexto linguístico e extralinguístico de um proferimento que percebemos qual dos sentidos a palavra "igreja" está denotando. Mas, por ser um exemplo de palavra polissêmica, todos esses diferentes sentidos se relacionam semanticamente e é possível perceber relações básicas convergentes entre eles.

Assim, os diferentes significados da palavra "igreja" estabelecem um vínculo entre eles por meio do sentido de "igreja" como instituição religiosa. Esse sentido está imprescindivelmente presente em todos os outros, pois, para a palavra "igreja" ter o sentido de espaço físico, é preciso que ela represente uma instituição religiosa, bem como para significar um grupo de pessoas religiosas, é preciso que esse grupo pertença a uma instituição religiosa. Dessa forma, todos os significados diferentes do termo possuem, claramente, um ponto de convergência partilhado, representado pela letra $g$ - instituição religiosa.

Figura 1: Diagrama de Venn representando a intersecção de significados do termo "igreja"

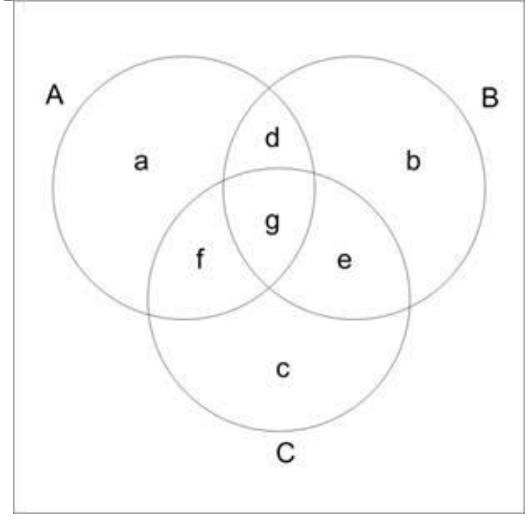

Fonte: Os autores

Outro exemplo de palavra polissêmica exposto no trabalho de Cambrussi e Poll (2015, p. 127) é o da palavra "tira". Ela pode ter dois ${ }^{2}$ significados diferentes: o primeiro, de "tira" como significado de pedaço de pano, de papel, etc. e o segundo, de "tira" como significado do gênero textual cômico, as famosas tirinhas que são histórias em quadrinho curtas. A relação comum de significado nesse exemplo diz respeito à estrutura do objeto "tira" de pano e do objeto "tira" gênero textual: ambos são mais compridos que largos, de modo que se apresentam de uma forma retangular razoavelmente curta. Além disso, mantém-se a mesma classe gramatical em ambas as leituras do item, i.e., "tira" é um substantivo.

Portanto, um item lexical é considerado polissêmico se os diferentes significados veiculados por ele estão relacionados a um eixo de significação e, além disso, se a classe gramatical do item não se modifica quando ele é utilizado nessas diferentes acepções.

\footnotetext{
2 A gíria "tira", se referindo a policial, e "tira" do verbo "tirar" não são exemplos de polissemia, pois não possuem vínculo semântico que lhes garanta uma intersecção de sentidos.
} 


\subsection{AMBIGUIDADE POR HOMONÍMIA}

Contrariamente à polissemia, tratada na seção anterior, em que há uma certa convergência de sentidos entre as diferentes leituras veiculadas pela expressão analisada, a homonímia, para Lyons (1977, p. 27), é um fenômeno em que "palavras ou lexemas [...] têm a mesma forma, mas diferem no significado, e não apenas por terem significados diferentes, mas por serem completamente estranhos um ao outro". Em outras palavras, a ambiguidade por homonímia ocorre quando os significados veiculados por uma dada expressão não têm relação nenhuma. Devido a esse aspecto, como já mencionado na seção 1, Weinreich (1964) caracteriza a homonímia como ambiguidade contrastiva. E, além disso, Pustejovsky (1995), mencionado na seção 1.1, sugere que na homonímia há mudança de categoria lexical.

A ambiguidade lexical por homonímia é gerada por palavras homófonas, palavras homógrafas e os homônimos perfeitos.

As palavras homófonas são graficamente diferentes e possuem significados totalmente diferentes. No entanto, possuem o mesmo som, conforme se observa nos exemplos, a seguir: "assento" (para sentar) e "acento" (sinal gráfico); "caçar" (pegar animais) e "cassar" (cassar um mandato).

As palavras homógrafas possuem a mesma grafia, mas são foneticamente diferentes (possuem sons diferentes) e têm significados diferentes. Exemplos: "acordo" (normalmente acordo cedo - verbo acordar) e "acordo" (preciso fazer um acordo com a empresa substantivo); "acerto" (sempre acerto as perguntas da professora - verbo acertar) e "acerto" (vamos ao acerto de contas - substantivo).

Finalmente, os homônimos perfeitos são palavras que possuem a mesma grafia e o mesmo som. Esse fenômeno pode ser observado no item lexical "cedo". Exemplos: "Cedo" primeira pessoa do singular do verbo ceder (eu cedo meu lugar para idosos sentarem); "cedo" - advérbio de tempo (chegar cedo é uma virtude a ser cultivada).

Nesse ponto, consideramos importante ressaltar que, como visto nos exemplos apresentados acima, as palavras homônimas pertencem a diferentes grupos lexicais. Ilari (2002, p. 103) ratifica essa característica com mais exemplos: "[...] "pia” (lavatório) é um substantivo; ele "pia" (uma das tantas vozes de piar) é um verbo; e "pia" (piedosa) é um adjetivo".

Há, ainda, palavras que podem apresentar tanto homonímia quanto polissemia, como é o caso de "pasta", explorada por Bertucci (2015). A palavra "pasta" pode ser usada como "pasta de dente", "pasta de comer", "pasta de engraxar sapato", etc. Nesses contextos, o significado comum seria o de massa e não há mudança de classe gramatical, portanto, há polissemia.

O interessante é que a palavra pasta também pode ser usada como "pasta de couro" ou "pasta ministerial", cujo significado básico seria lugar específico. Ou seja, entre esses últimos itens também há polissemia. No entanto, ao comparar os dois "grupos" de "pasta", o primeiro com sentido comum de massa e o segundo com sentido de lugar específico, não há acepções de significado em comum e, portanto, entre esses dois grupos, pode-se dizer que há homonímia. Assim, há palavras que podem apresentar os dois tipos de ambiguidade lexical. O objetivo desta investigação é descobrir em que classe de ambiguidade encaixa-se a palavra "negócio". 


\section{MÉTODO E CORPUS DA PESQUISA}

A investigação realizada neste artigo foi desenvolvida através da pesquisa e da coleta de dados da modalidade escrita, especificamente sentenças ${ }^{3}$, do PB contendo o item lexical "negócio". As análises deram-se a partir de dados:

(i) retirados de dicionários impressos, online, e de gramáticas;

(ii) coletados de contextos reais de uso de sites da internet;

(iii) elaborados pelos autores da pesquisa, falantes nativos do PB.

Tendo em vista que temos por meta analisar se o item lexical "negócio" possui ambiguidade por polissemia ou por homonímia, faz-se necessário que, primeiramente, apresentemos as acepções já sedimentadas do termo, uma vez que para se chegar aos contextos de uso é importante conhecer os sentidos já dicionarizados para somente, então, dar sequência à análise e, finalmente, descobrir se "negócio" é polissêmico ou homonímico, ou ainda pertence às duas classes.

Considere os dados encontrados no dicionário Michaelis online da Língua Portuguesa (2018) ${ }^{4}$.

ne.gó.cio

1 Comércio, tráfico, transação comercial. 2 Contrato, ajuste. 3 Qualquer casa

comercial. 4 Empresa. 5 Questão pendente; pendência. 6 pop. Coisa, objeto. 7 pop. Qualquer coisa cujo nome não ocorre no momento.

Considerando o excerto acima, podemos separar os sentidos 5 de "negócio", para fins de análise, em dois grupos: sentidos usuais em contexto formais - fazer comércio, realizar uma transação comercial, etc; e significações utilizadas em contexto informais, acepções 6 e 7.

No último grupo, um aspecto digno de nota é que o termo "negócio" veicula um significado genérico, i.e., não determina a um objeto ou entidade particular no mundo. $\mathrm{Na}$ verdade, pode se referir a qualquer coisa que o falante não saiba nomear no momento do proferimento, como em (11). Note também que "negócio" só faz referência a entidades inanimadas, i.e., com um traço [- animado], por isso a sentença em (12) é inadequada para o contexto, enquanto (11) é adequada.

Contexto: Chegando ao trabalho, João lembra que deixou o presente de aniversário de Clara em casa.

(11) Não acredito! Esqueci o "negócio” da Clara em casa!

Contexto: Pedro ficou de dar uma carona a um colega de trabalho. Ao chegar à

\footnotetext{
${ }^{3}$ Acreditamos que as sentenças contendo o item lexical "negócio" fornecem suficiente material linguístico para uma análise efetiva das suas possíveis significações.

${ }^{4}$ No Novo Dicionário da Língua Portuguesa (1986), escrito pelo gramático Aurélio Buarque de Holanda Ferreira, a palavra negócio possui definições similares:

"Negócio. [Do lat.negotiu.] S.m. 1. Comércio, tráfico, negócio de bebidas. 2. Relações comerciais; negociação, transação: Tem negócio com uma firma do Pará. 3. Convenção, combinação. 4. Empresa, ajuste, questão: $O$ negócio foi resolvido com agrado geral. 5. Negócio vantajoso; bom negócio: Aquele apartamento por 500 mil cruzados não é um bom negócio. 6. Caso, coisa; assunto; fato: De que negócio você está falando (DE HOLANDA FERREIRA, 1986, p.1187).

5 As significações de "negócio" listadas são as que estão disponíveis aos falantes do PB. Assim, toda vez que estiverem em contextos de enunciação, o falante e o ouvinte escolherão qual das concepções de "negócio" é a mais adequada para a situação.
} 
empresa, ele percebe que se esqueceu do combinado.

(12) \# \# $^{6}$ ão acredito! Esqueci de pegar o "negócio"!

A seguir, apresentamos exemplos de acepções de "negócio" (que serão discutidas na seção 3) cujos dados formam nosso corpus de análise:

a) $\mathrm{O}$ termo pode ocorrer com o sentido das palavras meta, objetivo, vontade ou desejo:

(13) O "negócio" é pensar em longo prazo.

(14) Meu "negócio" era jogar bola, molecagens em geral.

(15) O "negócio" é tocar em frente porque a nenê precisa do meu melhor.

(16) O "negócio" deles é viver na canoa.

b) A palavra "negócio" pode significar coisa ou algo, ou está no lugar de um nome (substantivo) que o locutor não sabe ou não lembra no momento da enunciação:

(17) Eu queria falar um "negócio" sobre o trabalho de Geografia.

(18) A professora ensinou um "negócio" lá.

c) A palavra "negócio" serve como elemento de uma sentença introdutória, aquela que introduz e aponta para uma narração ou mesmo a uma sentença que será enunciada a seguir pelo locutor, com uma estrutura de oração subordinada substantiva apositiva:

(19) O "negócio" é o seguinte: você gosta de sushi?

(20) Aconteceu um "negócio" muito interessante... (Começa-se a narrativa a partir daí).

d) "negócio" serve como variação informal de questão (como em (27)) e, em alguns casos, comporta-se como um elemento anafórico (como em (28)), ou seja, assume um papel de pronome retomando, total ou parcialmente, um termo ou entidade já mencionada ${ }^{7}$ (num processo de encapsulamento anafórico).

(21) Esse "negócio" da dupla personalidade explicaria quem dos personagens, enfim, tem o tal "irmão gêmeo".

(22) [...] e ele é um padre espetacular, ele fala muito bem, sabe, até o meu marido que não gosta de missa, não gosta de saber nada desses "negócios", ele gosta da missa de lá.

e) O termo "negócio" pode aparecer em construções como: "negócio" $d e^{8}+$ substantivo ou verbo no infinitivo, como em "negócio" de cursinho, "negócio" de

\footnotetext{
${ }^{6}$ Nesse caso, o símbolo '\#’ indica inadequação semântico-pragmática.

7 "Negócio", assim, parece ser um bom recurso para realizar anáforas complexas. Exemplos desse fenômeno são os pronomes demonstrativos e sintagmas nominais como situação, circunstância, fenômeno. Para mais informações sobre esse tema, ler os estudos de Koch (1999) na área da referenciação.

${ }^{8}$ Nesses casos, "negócio + de" forma uma expressão que parece ter um conteúdo semântico cristalizado e, por isso, o seu significado pode estar atrelado à junção das duas palavras e não exclusivamente à ocorrência do termo "negócio". Tais usos foram trazidos à tona porque constituem construções bastante utilizadas pelos falantes do PB.
} 
latim, "negócio" de fumar, "negócio" de cultura. Nesses casos, o termo "negócio" parece estar no lugar de uma entidade cujo nome não está acessível ao falante.

\section{DISCUSSÃO SOBRE “NEGÓCIO” E OS TIPOS DE AMBIGUIDADE}

A partir dos diferentes significados da palavra "negócio", apontados na seção 2, podemos afirmar que estamos diante de um caso de ambiguidade lexical. Porém, é necessário verificar qual o tipo de ambiguidade - homonímia ou polissemia - desenvolvida pelo item. Pretendemos esclarecer tal aspecto pretendemos nesta seção.

\section{1 "NEGÓCIO": AMBIGUIDADE POR HOMONÍMIA?}

Após uma análise dos significados dicionarizados do termo "negócio", percebemos que a maioria deles não possui traços comuns de sentido, o que nos leva a concluir que a palavra "negócio" desenvolve, na maioria dos casos, ambiguidade por homonímia. Isso pode ser comprovado, por meio dos seguintes exemplos, em que "negócio" significa transação comercial (seu sentido denotativo), objetivo e algo/alguma coisa que não se saiba ou não se pode nomear:

(23) Esses caras são demais, essa empresa é excelente, fazer "negócio" com brasileiro é ótimo. (transação comercial)

(24) O "negócio" é tocar em frente porque a nenê precisa do meu melhor. (objetivo)

(25) Eu queria falar um "negócio" sobre o trabalho de Geografia. (coisa, algo)

Perceba que nesses exemplos os significados não são relacionados, nem interligados, i.e., as diferentes acepções não têm um eixo significativo em comum.

Essa ideia se mantém nas situações, exemplificadas abaixo, em que o item lexical "negócio" assume um significado similar ao de assunto, acepção que também não se relaciona ao sentido denotativo do termo, i.e., atividade comercial:

(26) Quando estou com meus amigos, meu "negócio" é relembrar o passado.

(27) Se o "negócio" contar com mais de dez empregados, o dono terá de contratar um jovem aprendiz.

Por fim, também não há intersecção significativa entre as acepções de "negócio" como questão pendente em (28) e como objetivo, meta ou sonho em (29).

(28) Nossa ideia é resolver o mais rápido possível esse "negócio" de divergências entre currículos de cursos de informática.

(29) Percebe-se que o "negócio" dele é não fazer nada.

Como vimos na seção 1.2, a ambiguidade por homonímia pode se dar por meio de palavras homófonas, homógrafas ou por homônimos perfeitos. O termo alvo deste artigo pode ser classificado como um homônimo perfeito, pois é tanto graficamente como foneticamente idêntico em todos os seus contextos de uso, independentemente do fato de possuir significados completamente diferentes. No entanto, Pustejovsky (1995) sugere que na homonímia há mudança de categoria lexical, mas essa alteração não ocorre nos contextos em que "negócio" é utilizado: o item permanece sendo um substantivo em todos os casos que temos em mãos.

Portanto, tendo em vista as diferentes acepções de "negócio" discutidas nesta seção, concluímos que o item lexical desenvolve ambiguidade por homonímia, já que os significados 
descritos não possuem um eixo significativo em comum. Além disso, "negócio" é um homônimo perfeito porque é foneticamente e graficamente idêntico em todos os contextos em que aparece. Desse modo, será que podemos afirmar que "negócio" não desenvolve ambiguidade por polissemia, i.e., será que nenhuma das acepções do termo "negócio" possui traços de significado comum? Essa questão será esclarecida na seção seguinte.

\section{2 "NEGÓCIO": AMBIGUIDADE POR POLISSEMIA?}

Nesta seção analisaremos a possibilidade de o item lexical "negócio" também apresentar sentidos em que se observa ambiguidade por polissemia, cuja característica principal é haver alguma intersecção de sentido entre os usos diversos do item.

Por meio de análise atenta, podemos encontrar acepções básicas do termo "negócio" que se relacionam semanticamente, tais como: "negócio" como campo de atuação específico x "negócio" como empreendimento comercial (sentido denotativo do termo). Essa associação semântica pode ser percebida nos exemplos (30) e (31), a seguir:

(30) Meu "negócio" é jogar futebol.

(31) O "negócio" da família, deixado pelos pais dele, vai bem.

É correto afirmar que "negócio", quando empregado como "empreendimento comercial" também traz consigo a carga semântica de "campo de atuação específico", pois ambos se relacionam com a ocupação da pessoa e pela qual ela obtém retorno financeiro. Em (30), especificamente, o campo de atuação do falante é ser jogador de futebol, o que não deixa de ser o seu empreendimento comercial, já que desse ofício ele obtém o sustento. Já em (31), "negócio" veicula o sentido de empreendimento comercial, campo em que se realizam transações financeiras. Ou seja, há traços semânticos comuns entre as duas acepções de "negócio" em (30) e (31).

Outro caso de polissemia pode ser representado pelo seguinte par de sentenças:

(32) Eu queria falar um "negócio" relacionado ao trabalho de Geografia.

(33) Jorge tem um "negócio" importante para entregar ao seu pai.

Em (32) e (33), o item lexical está sendo usado de modo que não identifica o referente do termo, seja porque o falante não deseja particularizar o referente (como quando queremos tratar de um assunto e não desejamos que os outros saibam o teor da conversa e dizemos: 'Vem aqui, quero te falar um "negócio"') ou porque naquele momento ele não consegue nomear a entidade (por esquecimento ou desconhecimento) a qual deseja se referir (como quando vemos um objeto sobre a mesa e dizemos: 'Qual o nome daquele “negócio" ali?').

Em (32), o item "negócio" tem acepção de assunto não-especificado e, em (33) de objeto não-especificado. Sendo assim, em ambos os casos há uma intersecção de significação - a não-especificação. Em outras palavras, não é possível/desejável identificar o referente da expressão em nenhuma das sentenças. Sendo assim, podemos classificar a ambiguidade gerada entre (32) e (33) como polissemia.

Como vimos até aqui, a palavra "negócio" pode significar (i) área de atuação e empreendimento comercial, ambos unidos semanticamente pelo campo relacionado ao retorno financeiro, e (ii) assunto/objeto não especificado, e substitui um substantivo que o locutor não sabe/deseja nomear, unidos semanticamente pelo traço da "não-especificação" do referente.

Analisando as sentenças de (30) a (33) e comparando os sentidos de "negócio" temos que: 
(i) o par (30) e (31) possui uma acepção de significado comum relacionado ao retorno financeiro - apresentando ambiguidade por polissemia;

(ii) o par (32) e (33) possui acepção de significado comum relacionado à não especificação do referente - apresentando ambiguidade por polissemia;

(iii) os pares quando comparados entre si apresentam homonímia, pois não possuem uma intersecção semântica.

Uma vez discutidos e analisados esses dois grupos de exemplos, vemos que, em certas ocasiões e contextos, a palavra "negócio" assume também a ambiguidade por polissemia. De acordo com Ravin e Leacock (2000), isso não seria um problema para as áreas de estudos dedicadas ao uso da linguagem (análise do discurso, pragmática, análise da conversação, etc). No entanto, tal aspecto é uma dificuldade para as áreas da lexicografia e da tradução. Por isso, há testes para se diferenciar quando é polissemia e quando é homonímia, como o teste da identidade ${ }^{9}$ (elaborado por Lakoff (1970) para distinguir sentenças ambíguas de sentenças vagas) e mostrado por Ferraz (2014). Esse teste consiste em realizar uma elisão de um, ou mais, constituinte incluindo o termo ambíguo, como ocorre abaixo:

(34) Ana estava no "banco" e Pedro também.

(35) Ana gosta da UFPB e Pedro também.

O termo "banco" possui, no mínimo, significados de "assento" e de "instituição financeira". Nesses exemplos de Ferraz, a autora explica que em (34) não há possibilidade de serem acessados esses dois significados de "banco" porque "as leituras que se têm são 'Se Ana estava em alguma instituição financeira, Pedro também estava'; 'Se Ana estava em um assento, Pedro também estava' (2014, p. 130). Como não há possibilidade de, na mesma sentença, haver referência aos dois significados de "banco", trata-se de um caso de homonímia.

Já o termo "universidade" se comporta analogamente à "igreja", anteriormente analisada, e que possui, conforme a autora, três significados: o espaço físico, a instituição e as pessoas que fazem parte da instituição. Assim, em (35), poderia haver a seguinte leitura "“Ana gosta do prédio da UFPB e Pedro gosta do sistema de aulas"” (FERRAZ, 2014, p. 131). Vemos que, com essa leitura, seriam acessados dois significados diferentes de "universidade" na mesma sentença: "prédio" e "sistema de aulas", o que, por sua vez, configura a polissemia.

Aplicando esse teste ao exemplo (30), analisado nesta seção, temos (36), abaixo:

(36) Meu "negócio" é jogar futebol e o do João também.

O termo "negócio", como visto, dentre outros, possui dois significados: "empreendimento comercial" e "campo de atuação específico", ambos compartilhando uma relação semântica de retorno financeiro. Nesse caso, uma paráfrase da leitura de (36) poderia ser "Meu retorno financeiro vem de jogar futebol e o do João também", ou ainda, "Meu empreendimento comercial e o campo de atuação de João é jogar futebol". E, portanto, ambos remetem ao retorno financeiro, configurando, assim, um caso de polissemia.

Agora, aplicando o teste da elipse à sentença já exemplificada em (15), acima, em que "negócio" aparece com sentido de "objetivo", temos (37):

(37) *10 $\mathrm{O}$ "negócio" é tocar em frente porque a nenê precisa do meu melhor e o meu

\footnotetext{
${ }^{9}$ Ferraz (2014) também aponta que o teste de identidade de Lakoff (1970) não é uma unanimidade na literatura, mas fornece uma pista para diferenciarmos polissemia de homonímia.

${ }^{10} \mathrm{O}$ asterico marca uma sentença agramatical.
} 
também.

Repare que se consideramos os significados de "negócio" como "transação comercial" e como "objetivo" não há como acessá-los na mesma sentença, i.e., em (37), que só teria a seguinte leitura: "O objetivo é tocar em frente porque a nenê precisa do meu melhor". Perceba que neste contexto linguístico, o sentido de "transação comercial" nem poderia ser acessado: "\#A minha transação comercial é tocar em frente porque a nenê precisa do meu melhor". Desse modo, na sentença (37), não é possível acessar os dois significados, o que resulta, dessa forma, em um caso de homonímia.

Portanto, esse teste corrobora o que viemos afirmando: que "negócio" é uma palavra ambígua e que pode alternar usos com polissemia e usos com homonímia. Assim sendo, o item lexical "negócio" é daquelas palavras, tal como "pasta", que pode figurar nos dois tipos de ambiguidade.

\section{CONSIDERAÇÕES FINAIS}

Apesar de o termo "negócio" ser utilizado produtivamente e frequentemente em contextos informais, ele não pode ser considerado um item lexical semanticamente simples. Afinal, após as análises dos diferentes sentidos que "negócio" pode assumir que tal palavra suscita leituras complexas que merecem uma análise e descrição mais apurada, que até o presente artigo não tinha sido feita. Após a análise dos contextos em que "negócio" aparece e as significações que o item lexical assume em cada um deles, reforça-se a tese de que as palavras não possuem um significado a priori, elas adquirem significação quando as utilizamos nas interações. O contexto linguístico e extralinguístico é crucial para que se compreenda e se analise as expressões linguísticas, visto que alteram seu significado substancialmente. Sendo assim, as expressões linguísticas não podem ter seu significado reduzido às suas definições dicionarizadas, posto que nos inúmeros contextos (formais ou informais, linguísticos ou extralinguísticos) nos quais elas figuram, fazem com que elas assumam diferentes roupagens semânticas. Desse modo, enriquecem-nas semanticamente e as tornam instrumentos linguísticos adequados às mais variadas finalidades e situações.

Mas, afinal, esse "negócio" é polissemia ou homonímia? Diante de um 'ou' exclusivo, a resposta é negativa, pois nesse caso "negócio" somente pode pertencer a um conjunto - ou homonímia ou polissemia. Se estivermos diante de um 'ou' inclusivo, equivalente a uma conjunção aditiva 'e', a resposta é "sim", i.e., "negócio" veicula ambiguidade por homonímia e por polissemia a depender do contexto em que está inserido. Sendo assim, para que a pergunta reflita os achados semânticos descritos neste artigo, seria melhor se a reescrevêssemos como: Então, afinal, esse "negócio" é polissemia e homonímia? Sim, dependendo do contexto, esse "negócio" é polissemia e homonímia.

\section{Referências}

ARISTÓTELES. Organon VI Elencos Sofísticos. In: ARISTÓTELES. Os pensadores. São Paulo: Nova Cultural, 1996.

BERTUCCI, R. A. Introdução à análise da língua portuguesa: processos sintáticos e semânticos. Curitiba: InterSaberes, 2015.

CAMBRUSSI, M. F.; POLL, T. V. H. Ambiguidade Lexical em Tirinhas: Polissemia e Efeito de Humor. Revista (Con)textos Linguísticos, v. 9, n. 13, p. 123-140, 2015. 
COMÉRCIO. In: Dicio - Dicionário Online de Português. Disponível em: < https://www.dicio.com.br/comercio/>. Acesso em: 18 jan. 2018.

FERRAZ, M. M. T. Homonímia ou polissemia? Contribuições da semântica lexical para a organização de dicionários. In: ARAGÃO NETO, M.M, CAMBRUSSI F. (org). Léxico e gramática: novos estudos de interface. Curitiba, PR: CRV, 2014. p.123-141.

FERREIRA, A. B. de H. Novo Dicionário da Língua Portuguesa. Rio de Janeiro: Editora Nova Fronteira, 1986.

KOCH, I. G. V. A referenciação textual como estratégia cognitivo-interacional. In: BARROS, K. S. M,. Produção Textual: interação, processamento, variação. Natal: Edufurn, p. 69-80, 1999.

ILARI, R.; GERALDI, J. W. Semântica. São Paulo: Ática, 1987.

LAKOFF, G. A note on ambiguity and vagueness. Linguistic Inquiry, n.1, p. 357-359, 1970.

LYONS, J. Lingua(gem) e linguística - uma introdução. Rio de Janeiro: Livros Técnicos e Científicos Editora S. A., 1987.

LYONS, J. Semântica. Vol. 1. Traduzido por Wanda Ramos. Lisboa: Editorial Presença/Martins Fontes, 1977.

"NEGÓCIO". In: Michaelis Dicionário Brasileiro de Língua Portuguesa. Disponível $\mathrm{em}:<\mathrm{http}: / /$ michaelis.uol.com.br/busca? $\mathrm{r}=0 \& \mathrm{f}=0 \& \mathrm{t}=0 \&$ palavra $=$ neg $\% \mathrm{C} 3 \% \mathrm{~B} 3 \mathrm{cio} \geq$. Acessado em: 18 jan. 2018.

PUSTEJOVSKY, J. The generative lexicon. Cambridge: MIT, 1995.

RAVIN, Y.; LEACOCK, C. Polysemy: an overview. In: RAVIN, Y; LEACOCK. Polysemy: theoretical and computational approaches. Oxford: OUP, p.1-29, 2000.

WEINREICH, U. Webster's third: a critique of its semantics. In.: International Journal of American Linguistics, p. 30-405, 1964.

Letícia Lemos Gritti leticiagritti@utfpr.edu.br

Sandra Mara Fernandes dos Santos san_rgs@hotmail.com

Lovania Roehrig Teixeira lovaniateixeira@gmail.com

Robson Deon robson_deon@hotmail.com

Recebido em: 27 fev. 2019

Aceito em: 10. Abril. 2019

Publicado em: Junho de 2019 